\title{
Obtenção de fotografias aéreas de pequeno formato e videografia por meio de aeromodelo artesanal adaptado
}

\author{
Obtaining small-format aerial photography and videography \\ using an adapted handcrafted model airplane
}

Paulo Costa de Oliveira Filho[ ${ }^{[a]}$,Flaubert Agostinho[ ${ }^{[b]}$

[a] Engenheiro florestal, Dr., Departamento de Engenharia Ambiental da Universidade Estadual do Centro-Oeste, Irati, PR Brasil, e-mail: paulocostafh@gmail.com

[b] Engenheiro ambiental, Departamento de Engenharia Ambiental da Universidade Estadual do Centro-Oeste, Irati, PR Brasil, e-mail: flaubertagostinho@hotmail.com

\section{Resumo}

Esta pesquisa objetivou implementar um sistema gerador de fotografias aéreas de pequeno formato, bem como imagens de videografia em áreas restritas ou pontuais, de baixo custo, obtidas a partir de uma câmera digital portátil comum acoplada a um aeromodelo artesanal de madeira de baixa densidade. Foram realizadas várias adaptações na aeronave para a inserção de uma cápsula blindada, porém leve, e de madeira de baixa densidade com tampa de vidro, na parte inferior da fuselagem da aeronave, para acomodar a câmera. Outras adaptações foram realizadas para possibilitar o disparo das fotos e acionamento da filmagem a distância, por meio do controle remoto, bem como para equilibrar a aeronave em voo. Os voos foram realizados em área rural do município de Irati, PR, distante cerca de $15 \mathrm{~km}$ da área urbana. Foram realizados vários voos até a calibragem necessária do aeromodelo, para que se adquirisse máxima estabilidade em voo. Foram obtidas fotografias aéreas digitais de pequeno formato, as quais foram mosaicadas no aplicativo InkScape versão 0.46 , bem como imagens de videografia. A vibração do motor da aeronave mostrou ser fator limitante quanto à qualidade das imagens, o que resultou em grande perda de informação, aspecto que pode ser aprimorado. Apesar da falta de controle geométrico e de faixas de voo, os resultados mostraram-se promissores em trabalhos pontuais, para estudos de impacto ambiental e análises preliminares.

Palavras-chave: Veículo aéreo não tripulado. Recobrimento aéreo. Áreas restritas.

\section{Abstract}

This research aimed to develop a device that generates small-format aerial photography and videography images in restricted or limited areas at low-cost, using a common digital camera attached to a model aircraft made of low density wood. Several adjustments were needed to mount the aircraft with a lightweight armored capsule made of low-density wood fitted with a glass cover at the bottom of the fuselage in order to house the camera. Other 
adjustments were made to allow remote photo shooting and video recording using a remote control as well as to balance the aircraft during flights. Flights were conducted over a rural area of Irati, State of Paraná, Brazil, about $15 \mathrm{~km}$ distant from the urban area. Several flights were performed to calibrate the model aircraft to achieve maximum stability during flight. Small-format aerial shots were obtained and subsequently mosaicked using InkScape version 0.46 software, as well as videography images. Vibration of the aircraft engine was considered a limiting factor to the quality of image, resulting in significant loss of information, an aspect that can be improved in future developments. Despite the lack of geometric control and of flight strips, results suggest that the device is promising for limited work such as environmental impact studies and preliminary analyses.

Keywords: Unmanned aerial vehicle. Aerial covering. Restricted areas.

\section{Introdução}

A prática do aeromodelismo (aeronave não tripulada) vem sendo cada vez mais desenvolvida e utilizada no Brasil para produção de imagens aéreas. No entanto, tal equipamento não surgiu para esse fim, sendo sua primeira produção em larga escala destinada a fins militares. Os primeiros registros da utilização de veículos aéreos não tripulados em cenário de guerra (RPAV, 2003) são de agosto de 1849, quando os austríacos atacaram a cidade italiana de Veneza com balões não tripulados carregando explosivos controlados por temporizadores. No entanto, conforme Naugghton (2005), a primeira produção em larga escala de VANT (veículos aéreos não tripulados) foi feita por Reginald Denny, que havia servido à Força Aérea Britânica na Primeira Guerra Mundial. Após a guerra ele emigrou para os Estados Unidos e montou as indústrias Reginald Denny, que produzia as aeronaves rádio-controladas. Como já relatado, embora o aeromodelismo tenha surgido com a finalidade de ser utilizado em ataques de guerra, com o passar do tempo passou a servir a outros fins.

Segundo Gonçalves-Junior, Piovesan e Silveira (2003), uma forma prática, barata e rápida de obter fotografias aéreas de uma pequena área com câmaras comuns, consiste em acoplar câmaras em aeronaves rádio-controladas (aeromodelos), e determinar uma altura do voo, velocidade do aeromodelo, tempo de obtenção das fotos e tipo de filme utilizado, de acordo com a área de interesse, para que o produto final possa ser utilizado da melhor maneira possível. Se corretamente obtidas, essas fotos terão qualidade suficiente para permitir uma fotointerpretação adequada, de onde se podem extrair as informações de interesse. A partir disso, pode-se pensar que a utilização de fotografias aéreas de pequeno formato na identificação de áreas restritas de preservação permanente (APPs) pode ser uma alternativa à utilização de cenas de alta resolução espacial obtidas a partir de sensores orbitais (GONÇALVES et al., 2005).

A utilização de métodos tradicionais para a obtenção de fotografias aéreas em situações em que se deseja obter informações de áreas restritas pode não ser economicamente viável, comparando ao uso de aeronaves rádio-controladas. Dependendo da finalidade do estudo, imagens provenientes de câmeras fotográficas comuns podem render ótimos resultados, dispensando toda a aparelhagem apropriada e específica dos aerolevantamentos convencionais, e consequentemente barateando todo o processo.

Com o uso de aeromodelos, o processo de obtenção de fotos aéreas passa a ser uma alternativa para tomadas aéreas pontuais ou mesmo imagens de videografia, contudo, deve-se considerar as perdas na qualidade do produto final, uma vez que o voo não é totalmente controlado e a aeronave está sujeita a desalinhamento, derrapagens, entre outras consequências da instabilidade provocada por intempéries. Como também acontece na aviação, no aeromodelismo fatores climáticos podem gerar alterações de posicionamento e no curso da aeronave durante o voo, alterações essas que podem gerar erros na obtenção das imagens. Mesmo com sua margem de erro, dependendo da utilização das imagens e da área em estudo, seu uso ainda pode ser viável em algumas situações, como, por exemplo, publicidade e turismo, inspeção de pequenas áreas ou a noção inicial de uma área degradada.

No processo de cartografia tradicional, as condições de clima (vento, nuvens) e pilotagem não permitem que o avião mantenha sua altitude constante, 
bem como a velocidade do avião e a horizontalidade das asas. Esses fatores afetam a obtenção de um modelo "ideal" para a estereofotogrametria. Ou seja, mesmo usando dados supostamente controlados (no caso tradicional), o que se obtém é um modelo mais ou menos próximo do ideal, com pequenas distorções. Isso se agrava ainda mais no caso da obtenção de dados não controlados. Assim sendo, um dos prejuízos na utilização de aeromodelos para fotografias é que as imagens são geradas por câmeras comuns transportadas por aeromodelo, que podem sofrer distorções graças à instabilidade do voo, o que é comum e frequente não só durante a obtenção de imagens (GONÇALVES, 1995).

A aerofotogrametria é uma técnica vastamente difundida e utilizada em mapeamentos. Sua qualidade é indiscutível e seus métodos vêm evoluindo constantemente. Essa qualidade deve-se muito ao fato da alta precisão das câmeras utilizadas e dos sofisticados recursos eletrônicos e computacionais, que trabalham em conjunto com um minucioso sistema de lentes ou sensores do tipo CCD. Essas câmeras geralmente são instaladas em aeronaves convencionais ou helicópteros, e a obtenção de imagens de uma área depende de uma série de fatores que devem ser considerados na etapa de planejamento, antecedente ao voo. Todos esses procedimentos, mais as etapas posteriores ao voo, tornam o levantamento aerofotogramétrico uma técnica de alto custo, limitando sua utilização a projetos que abranjam grandes áreas, ou seja, que ao menos justifiquem o custo de um voo com aeronaves apropriadas e com câmeras métricas específicas. Esse tipo de voo depende também de fatores climáticos e autorizações do Departamento de Aviação Civil - DAC (GONÇALVES-JUNIOR; PIOVESAN; SILVEIRA, 2003). Entretanto, quando a área a ser analisada é reduzida e pontual, ou seja, limitada pela ação de um controle remoto, uma alternativa pode ser o uso de imagens obtidas por uso de VANT. No Brasil, os primeiros relatos de veículos aéreos não tripulados ocorreram na década de 80, quando o Centro Técnico Aeroespacial (CTA) desenvolveu o projeto Acauã. Atualmente, os projetos visando ao desenvolvimento de VANT autônomos são conduzidos pelos institutos de pesquisa CTA e Centro de Pesquisas Renato Archer (CenPRA). Tais pesquisas são realizadas com a finalidade de identificar anormalidades nas lavouras ou no mapa de produtividade, todas direcionadas à agricultura de precisão (MEDEIROS et al., 2008).
Segundo Antuniassi e Salvador (2002), a coleta de imagens para a identificação de manchas nas lavouras pode ser obtida de vários tipos de plataforma, tais como aeromodelos, balões e aeronaves de pequeno porte. As imagens aéreas de satélites e a videografia são ferramentas que também têm um grande potencial para identificação de manchas existentes nas lavouras, infestações de plantas daninhas, topografia e geração de mapas de produtividade (MOLIN, 2000).

0 objetivo do presente estudo foi desenvolver um sistema que produza imagens a partir de fotografias aéreas digitais e videografia, por meio de aeronave rádio-controlada não tripulada e adaptada que possibilite uma vista aérea em levantamentos prévios e pontuais.

\section{Materiais e métodos}

\section{Caracterização da área de estudo}

A área escolhida para a execução dos voos está localizada no município de Irati, PR, na localidade rural do Pinho de Baixo, normalmente bastante utilizada para a prática de aeromodelismo na região. As coordenadas geográficas centrais da área de estudo são Latitude $25^{\circ} 25^{\prime} 15^{\prime \prime}$ Sul e Longitude $50^{\circ} 48^{\prime} 43^{\prime \prime}$ Oeste.

O clima regional, conforme Köppen, é do tipo $\mathrm{Cfb}$ - subtropical úmido mesotérmico, caracterizado por verões frescos, geadas severas e frequentes e sem estação seca. A altitude média é de 915 metros. A área utilizada para os voos caracteriza-se pela ocorrência de culturas agrícolas e florestais, florestas nativas de araucária e construções rurais.

\section{Materiais}

Os materiais utilizados para realização da pesquisa foram:

a) câmera digital da marca Sony ${ }^{\circledR}$, modelo Cyber Shot DSC-W320 equipada com lentes Carl Zeiss;

b) cápsula blindada para acomodação da câmera adaptada à aeronave;

c) aeromodelo artesanal de madeira balsa e compensado aeronáutico;

d) motor OS 70 - 4 tempos;

e) rádio transmissor JR MAX-66; 
f) peso para balanceamento da aeronave;

g) haste adaptada para o acionamento da câmera em terra;

h) servomotor adaptado para o disparo remoto das fotografias e videografia;

i) combustível Glow 10\% (mistura de metanol, nitrometano e óleo lubrificante sintético);

j) bomba manual para abastecimento;

k) starter para ignição do motor;

l) bastão para a partida do motor.

A câmera digital possuía resolução máxima de 14.1 Megapixels, e continha um cartão de memória de $4 \mathrm{~GB}$, com uma capacidade de armazenamento de aproximadamente 700 imagens na sua resolução máxima e até 4.400 na resolução mínima, de 2 Megapixels. Na presente pesquisa, a câmera foi ajustada para trabalhar na faixa de resolução de 10 Megapixels, permitindo o armazenamento de 970 imagens ou cerca de uma hora de vídeo. A aeronave utilizada na pesquisa foi construída de forma artesanal. A Figura 1 exibe a aeronave e os demais componentes utilizados.
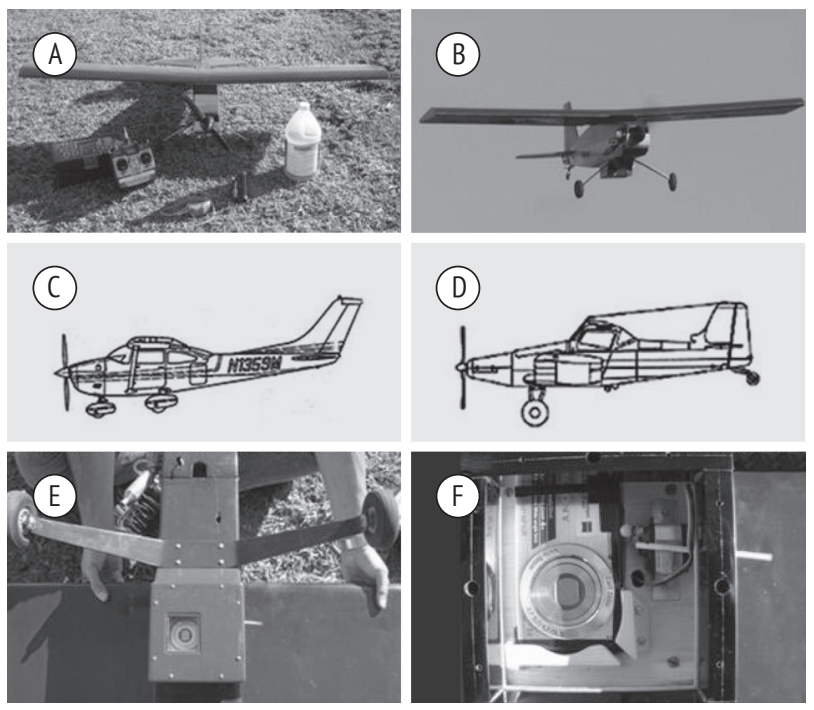

Figura 1 - Aeronave e demais componentes (A); aeronave em voo, com destaque para a cápsula blindada na parte inferior da fuselagem (B); exemplo de aeronave triciclo (C); exemplo de aeronave convencional (D); cápsula blindada para acomodação da câmera adaptada à aeronave (E); vista interna da cápsula blindada para acondicionamento e acionamento da câmera (F).

Fonte: Dados da pesquisa.
A Tabela 1 apresenta respectivamente as características técnicas da aeronave e custo total dos equipamentos utilizados. Os custos apresentados na Tabela 1 são extremamente baixos se comparados com outras técnicas e apenas servem como base para demonstrar que essa forma de obtenção de imagens da superfície do terreno é uma realidade não tão distante para as aplicações já descritas.

\section{Metodologia}

Para possibilitar o transporte da câmera, a aeronave sofreu algumas modificações, como redução do curso das superfícies móveis, as quais proporcionam a agilidade de movimento do avião no ar, a retirada do trem de pouso da posição triciclo (uma roda direcional na dianteira e trem de pouso principal no meio da fuselagem), para a posição convencional (trem de pouso principal mais adiantado na fuselagem e roda direcional presa ao leme, na traseira da

Tabela 1 - Características técnicas da aeronave e custo dos equipamentos

\begin{tabular}{|c|c|c|}
\hline \multicolumn{2}{|c|}{ Descrição do material } & Característica \\
\hline \multicolumn{2}{|c|}{ Peso sem equipamento fotográfico } & $3,500 \mathrm{~kg}$ \\
\hline \multicolumn{2}{|c|}{ Peso com equipamento fotográfico } & $3,720 \mathrm{~kg}$ \\
\hline \multicolumn{2}{|c|}{ Comprimento da fuselagem } & $117 \mathrm{~cm}$ \\
\hline \multicolumn{2}{|l|}{ Envergadura } & $170 \mathrm{~cm}$ \\
\hline \multirow[t]{4}{*}{ Motorização } & Cilindrada & $11.50 \Subset c$ \\
\hline & Rotações & 2000 a 12000 rpm \\
\hline & Potência & 1,1 HP a 11000 rpm \\
\hline & Peso & $570 \mathrm{~g}$ \\
\hline \multicolumn{2}{|c|}{ Capacidade do tanque de combustível } & $340 \mathrm{~mL}$ \\
\hline \multicolumn{2}{|l|}{ Autonomia } & 20 minutos \\
\hline \multicolumn{2}{|c|}{ Raio de operação da aeronave } & $1 \mathrm{~km}$ do rádio transmissor \\
\hline \multicolumn{2}{|l|}{ Material } & Custo (R\$) \\
\hline \multicolumn{2}{|l|}{ Motor } & 700,00 \\
\hline \multicolumn{2}{|c|}{ Rádio controle } & 500,00 \\
\hline \multicolumn{2}{|l|}{ Câmera } & 800,00 \\
\hline \multicolumn{2}{|c|}{ Material usado no modelo } & 400,00 \\
\hline \multicolumn{2}{|c|}{ Material usado na montagem } & 200,00 \\
\hline \multicolumn{2}{|c|}{ Galão de combustível (3,78 L) } & 60,00 \\
\hline \multicolumn{2}{|l|}{ Total } & $2.660,00$ \\
\hline
\end{tabular}

Fonte: Dados da pesquisa. 
aeronave). As posições triciclo e convencional estão demonstradas na Figuras 1C e 1D. As modificações no posicionamento do trem de pouso possibilitaram a instalação de uma pequena cápsula externa, que serve como suporte e proteção para a câmera, evitando que ela fique exposta ao vento, óleo expelido do motor, possíveis fragmentos de solo e pedras na decolagem e pouso, além de servir como proteção em um eventual acidente, já que a câmera fica totalmente enclausurada, como ilustra a Figura 1E.

Foi necessária uma adaptação do mecanismo de ativação da câmera em terra, após o acondicionamento e fixação da câmera na cápsula blindada, e de acionamento ou disparo das fotos ou vídeos em voo. Os detalhes da cápsula blindada estão apresentados nas Figuras 1B, 1E e 1F. Por ser um aeromodelo considerado trainer, ou seja, avião apropriado para iniciantes no aeromodelismo, ele proporciona um voo mais estável em baixas velocidades, fácil de ser controlado e apresentando manobras mais lentas, o que possibilita maior precisão na obtenção de imagens mais nítidas. Em relação ao mecanismo de disparo das fotos ou acionamento da filmagem, optou-se pela utilização de um servomotor semelhante aos utilizados nos outros comandos da aeronave, como acelerador, por exemplo, porém, em menores dimensões, o que facilitou seu posicionamento dentro da cápsula de proteção da câmera. Isso faz com que os disparos fotográficos ou de filmagem fiquem a critério do operador do aeromodelo. Apenas os processos de ativação e desativação da câmera são feitos de forma manual, por meio de um pequeno bastão externo conectado ao botão de acionamento da câmera, com a aeronave ainda em terra. Optou-se pela instalação do sistema fotográfico na superfície externa da aeronave, por sua motorização apresentar potência superior à necessária no levantamento da aeronave. 0 design da aeronave com linhas mais retas facilitou o processo de fixação da cápsula na parte inferior da fuselagem do avião. Essa fixação externa, além de não apresentar alterações consideráveis no vôo, evitou que, com a instalação interna do equipamento, fossem necessárias modificações na estrutura mecânica no interior do aeromodelo.

Foram realizados vários voos testes no local, para que fosse feita a calibragem do equipamento da aeronave em relação à estabilidade em voo. Ajustes foram necessários para corrigir o "peso de cauda" registrado nos primeiros voos, o qual foi sanado com o adiantamento da posição da bateria e receptor dentro da fuselagem da aeronave, além da fixação de um contrapeso em sua área frontal. Feitos os ajustes necessários, os voos foram realizados de forma a abranger uma área restrita, que pode variar em função do raio de alcance do controle remoto, sem nenhum planejamento prévio de curso, apenas procurando obter o máximo possível de tomadas aéreas em uma determinada altitude, da mesma forma, limitada pelo alcance do rádio-controle. Assim sendo, os voos foram realizados sobre um círculo com raio inferior ao alcance proporcionado pelo mecanismo de controle remoto. Voos distintos foram realizados obtendo-se material videográfico e fotográfico do terreno. Para evitar a perda do alcance do controle da aeronave, que tem uma distância controlada limitada a $1 \mathrm{~km}$, procurou-se evitar chegar muito perto desse limite, mantendo sempre a aeronave a um raio de ação bem visível, contornando sempre a área enfocada e restrita ao estudo. Dentro dessa premissa, foram realizados tanto voos videográficos quanto fotográficos, cujas imagens foram obtidas repetidamente para, em seguida, serem utilizadas na confecção de mosaicos não controlados elaborados no aplicativo InkScape versão 0.46.

\section{Resultados e discussão}

Embora apresente uma boa estabilidade e controle, a aeronave, bastante influenciada por fatores climáticos, variou sua altitude em alguns metros durante a tomada de cerca de 40 fotos. Dessas, quase $40 \%$ apresentaram uma escala não compatível com as demais e foram, portanto, descartadas.

Houve a eliminação também das fotos que não possuíam nitidez suficiente, provavelmente graças ao fator de arraste. A Figura 2A apresenta um mosaico elaborado com fotos obtidas de um voo que contornou a área de estudo de forma contínua, tirando fotos repetidas vezes. Elas foram selecionadas e mosaicadas.

Conforme pode ser verificado na Figura 2A, o mosaico não controlado de uma área irregular elaborado com diversas fotografias é importante fonte para possibilitar informações preliminares sobre a área de estudo, tais como o uso e cobertura atual da terra, extensão de um determinado alvo de estudo, extensão de algum acidente ambiental, entre outros. 

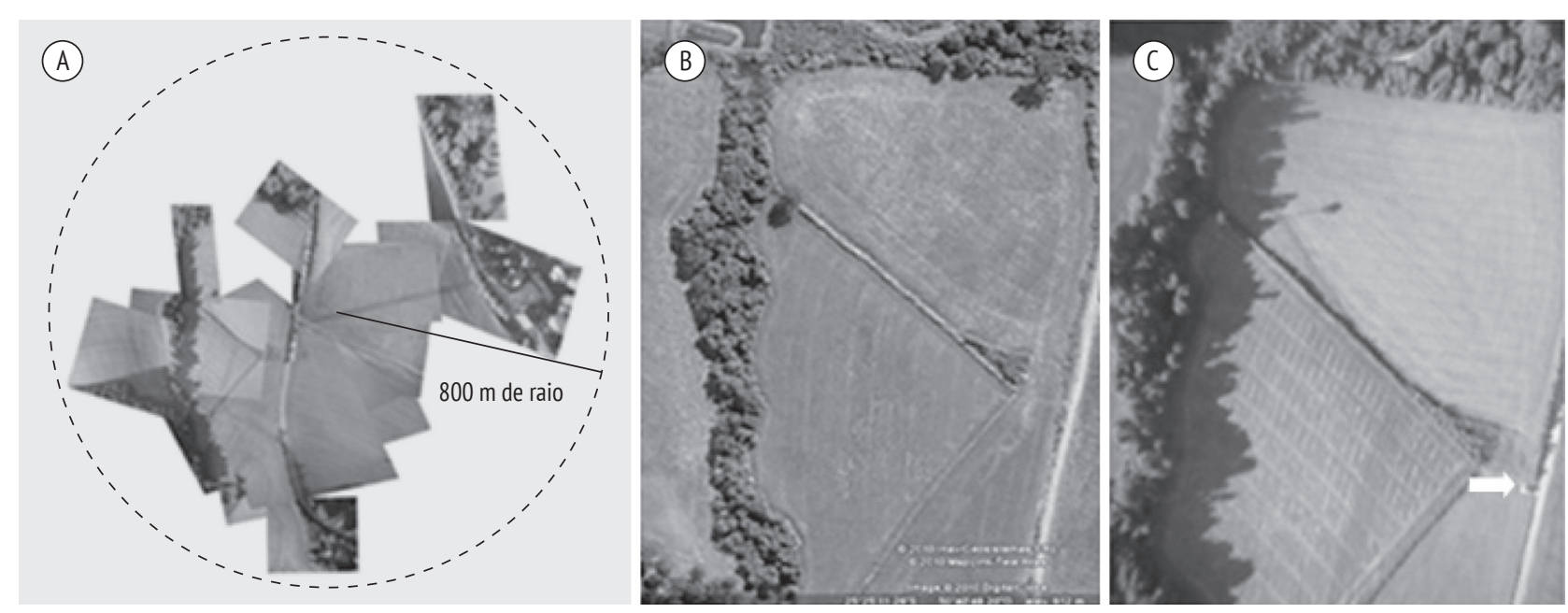

Figura 2 - Mosaico não controlado elaborado com uso do aplicativo InkScape 0.46 com uso de fotos aéreas obtidas pelo aeromodelo em uma área restrita de aproximadamente $800 \mathrm{~m}$ de raio (A); imagem correspondente obtida pelo software Google ${ }^{\circledR}$ Earth (B); e imagem de vídeo obtida pelo aeromodelo (C).

Fonte: Dados da pesquisa.

O mosaico da Figura 2A apresenta grande parte da área de alcance descoberta. Isso ocorreu em parte em função da perda de tomada aérea pelo tempo estimado para acionamento de disparo, que foi de 3 segundos para cada foto, ou então por perda de qualidade das imagens ocasionada pela vibração do motor, causando falta de nitidez de algumas fotos, ou simplesmente por movimentos indesejados da aeronave, graças a fatores climáticos. Mesmo assim, as possibilidades de utilização dessa técnica são reais, dentro de suas limitações, considerando sempre um maior controle sobre os fatores mencionados e procurando obter o máximo de fotografias para possibilitar, dentro do possível, o recobrimento da área restrita ao levantamento. A Figura 2C exibe uma cena de vídeo congelada, e, portanto, transformada em imagem, obtida por aeromodelo e ao lado a mesma área observada no Google ${ }^{\circledR}$ Earth.

A videografia com aeromodelo possibilitou, neste trabalho, resultados satisfatórios em relação ao esperado. 0 filme foi passado diversas vezes em laboratório, congelando-se algumas cenas e salvando imagens em disco. No canto inferior direito inferior da Figura 2B, em destaque na imagem de vídeo congelada e indicado por uma flecha branca, pode ser visualizado um ponto prateado que representa um automóvel de 4 metros de comprimento.

Pôde-se estabelecer uma escala linear média aproximada para a imagem de vídeo congelada, mesmo considerando a sua imprecisão. 0 automóvel localizado na imagem impressa aparece pouco visível e com aproximadamente $2 \mathrm{~mm}$ de comprimento. Sabendose que seu comprimento real é de $4 \mathrm{~m}$, tem-se uma escala média aproximada de 1:2.000. Em função do alcance do controle remoto, sabe-se que a distância máxima de controle é de $1 \mathrm{~km}$, portanto estima-se que o raio de distância de alcance utilizado foi de cerca de 800 a 900 m, por segurança. No entanto, não é possível obter dados mais precisos, diante de um voo sem controle total de altitude, e com imagens produzidas sem qualquer tipo de correção de suas distorções geométricas. Contudo, diante de uma situação em que a ênfase seja mais relacionada a um levantamento prévio para avaliação de impactos ambientais ou uma atualização do uso da terra em um determinado local, ou mesmo para ilustrar um trabalho com a visão atual de uma área restrita e perspectiva aérea, a tecnologia têm sua importância em trabalhos temáticos em que não haja nenhuma pretensão de cálculos de distâncias e áreas a partir das imagens.

\section{Conclusões}

- Foi possível implementar um sistema gerador de fotografias aéreas de pequeno formato, bem como imagens de videografia para áreas restri- 
tas, obtidas a partir de uma câmera digital comum acoplada a um aeromodelo de baixo custo com uso de aeromodelo artesanal adaptado.

- Essa metodologia mostra-se promissora em usos pontuais tais como levantamentos prévios para avaliação de impactos ambientais, atualização do uso da terra em um determinado local, ou mesmo para ilustrar um trabalho com a visão atual de uma área restrita e perspectiva aérea, análises preliminares sem pretensão de obter medições e considerando áreas restritas ao raio de alcance do controle remoto.

- A vibração do motor da aeronave mostrou ser fator limitante no aspecto qualidade das imagens, o que resultou em uma grande perda de informação.

- É importante ressaltar que é fundamental alguma experiência com aeromodelos tanto no momento de calibrar o avião, para que ele proporcione o voo mais estável possível, além da própria sensibilidade ao manipular o controle remoto da aeronave.

\section{Referências}

ANTUNIASSI, U. R.; SALVADOR, A. Análise de imagens aéreas para mapeamento de plantas daninhas em sistemas de agricultura de precisão. In: SIMPÓSIO INTERNACIONAL DE AGRICULTURA DE PRECISÃO, 2., 2002, Viçosa. Anais... Viçosa: UFV, 2002. 1 CD-ROM.

GONÇALVES-JUNIOR, J. C. C.; PIOVESAN, E. C.; SILVEIRA, G. C., SOFIA - Sistema de obtenção de fotos e imagens com aeromodelo. In: CONGRESSO BRASILEIRO DE CARTOGRAFIA, 21., 2003, Belo Horizonte. Anais... Belo Horizonte: [s.n.], 2003. 1 CD-ROM.
GONÇALVES, D. A. et al. Fotografias aéreas de pequeno formato aplicadas na identificação, quantificação e planejamento de recuperação de áreas de preservação permanente. In: SIMPÓSIO BRASILEIRO DE SENSORIAMENTO REMOTO, 12., 2005, Goiânia. Anais... INPE: Goiânia, 2005.

GONÇALVES, L. M. G. Reconstrução a partir de estéreo fotogrametria. Rio de Janeiro: [s.n.], 1995.

MEDEIROS, F. A. et al. Utilização de um veículo aéreo não-tripulado em atividades de imageamento georreferenciado. Ciencia Rural [online], v. 38, n. 8, p. 2375-2378, 2008.

MOLIN, J. P. Geração e interpretação de mapas de produtividade para a agricultura de precisão. In: BORÉM, A. et al. Agricultura de precisão. Viçosa: UFV, 2000. p. 237-257.

NAUGGHTON, R. Aviation and aeromodelling: independent evolutions and histories. 2005. Disponível em: <http://www.ctie.monash.edu.au/hargrave/denny.html>. Acesso em: 20 jun. 2011

RPAV - REMOTE PILOTED AERIAL VEHICLES. An anthology. 2003. Disponível em: <http://www.ctie.monash.edu. $\mathrm{au} /$ hargrave/rpav_home.html>. Acesso em: 25 out. 2010.

Recebido: $14 / 04 / 2011$

Received: 04/14/2011

Aprovado: $25 / 08 / 2011$

Approved: 08/25/2011 